\title{
TEMA 6-2016: Técnicas de reconstrucción nasal tras re- sección de un carcinoma basocelular
}

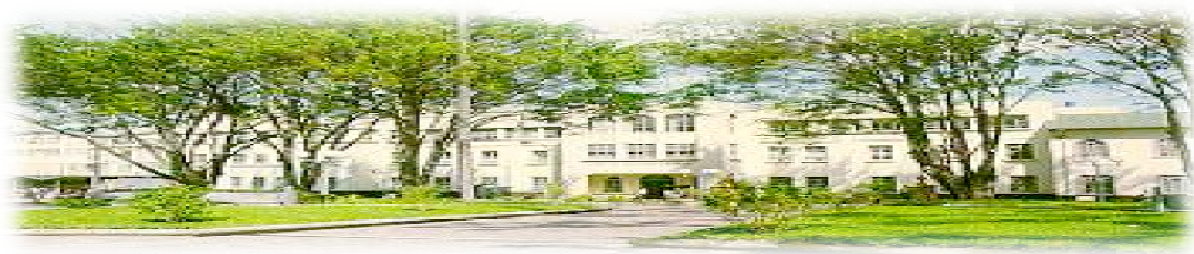

Hospital San Juan de Dios, San José, Costa Rica. Fundado en 1845

Recibido:

$11 / 11 / 2015$

Aceptado:

$29 / 11 / 2015$

Eduardo Brenes Leñero ${ }^{1}$

Loretta Piccolo Johanning ${ }^{2}$

${ }^{1}$ Médico Residente de Cirugía General, Universidad de Costa Rica. Hospital México, Caja Costarricense de Seguro Social, correo electrónico: eduardo_brenes@hotmail.com

${ }^{2}$ Médico Residente de Dermatología, Universidad de Costa Rica. Hospital San Juan de Dios, Caja Costarricense de Seguro Social, correo electrónico: loretta_piccolo@hotmail.com

\section{RESUMEN}

El cáncer de piel es la etiología más común causante de defectos nasales que van a requerir de una reconstrucción nasal. De estos, el carcinoma basocelular es el más frecuente.Esto presenta un gran grado de complejidad dado que se deben modificar tejidos para crear una estructura que aunque semeja una nariz, no lo es.Cualquiera de las capas estructuralmente importantes de la nariz que hacen falta deben ser reconstruidas, por esto el cirujano debe estar familiarizado con la técnica empleada.En esta revisión repasaremos las técnicas de reconstrucción más utilizadas.

\section{PALABRAS CLAVE}

carcinoma basocelular, reconstrucción nasal, injertos, colgajos.

\section{ABSTRACT}

Skin cancer is the most common cause of nasal defects that will require a nasal reconstruction, Of these, basal cell carcinoma is the most frequent one. Modifying tissues to create a structure that resembles a nose, even if it is not represents a great degree of complexity.Structurally important layers of the nose must be rebuilt, so the 
surgeon must be familiar with the technique being used. In this review we will review the most common reconstruction techniques used.

\section{KEY WORDS}

basal cell carcinoma, nasal reconstruction, grafs, flaps.

\section{DISCUSIÓN}

El carcinoma basocelular (CBC)corresponde a $75-80 \%$ de los cáncer de piel no melanoma. ${ }^{(1-}$ ${ }^{6}$ Es una neoplasia de piel no melanocítica que surge de las células basales de la epidermis o de folículos pilosos, y que al ser localmente invasiva y de crecimiento lento puede resultar en gran desfiguración cosmética. ${ }^{(1,2,5,7,8)}$

El CBC se observa más frecuentemente en zonas fotoexpuestas por la acumulación crónica de radiación ultravioleta. Ocurre principalmente en la cara, siendo más común en la nariz, específicamente en la punta nasal y las alas; y en pacientes de piel clara. ${ }^{(1,2,5,6,9)}$

En casi todos los casos el tratamiento es quirúrgico e incluye métodos como la cirugía micrográfica de Mohs, la escisión quirúrgica convencional, la criocirugía con nitrógeno líquido y la electrodisecación con curetaje. ${ }_{(1-3,5,6,8,10)}$ Las técnicas varían con base en el estadiaje, el subtipo, la localización, la disponibilidad del tratamiento, las comorbilidades y los deseos del paciente. ${ }^{(2,3,11,12)}$ En casos avanzados al igual que en aquellos no aptos para cirugía se pueden usar otras alternativas como la radioterapia, la terapia fotodinámica, o incluso tratamiento farmacológico en casos de CBC pequeños y de bajo riesgo. ${ }^{(1-}$

${ }^{3,5)}$ La meta del tratamiento seleccionado es asegurar una remoción completa del tumor, preservarla función y lograr un buen resultado cosmético, sin estenosis ni distorsión. ${ }^{(2,13,14)}$

La nariz es el aspecto más prominente de la cara; el área perinasal representa la personalidad de una persona, es un área cosmética y funcionalmente importante. ${ }^{(15-19)}$ Recordar que el paciente desea verse "normal", definido por la calidad de la piel y contorno tridimensional. ${ }^{(15,20)}$ La presencia o ausencia de cicatrices es de menor importancia. $^{(15)}$

El éxito de cada cirugía yace en los detalles. ${ }^{(9)} \mathrm{La}$ reconstrucción nasal que le sigue a un cáncer de piel debe de ser abordada de manera gradual, utilizando el método menos invasivo que puede reparar el defecto de la manera más apropiada. Se deben considerar las siguientes opciones: 1) cierre primario por planos, 2) cierre por segunda intención, 3) colgajos locales, 4) injertos de espesor parcial, 5) injertos de espesor total, 6) colgajos compuestos no vascularizados, 7) colgajos regionales vascularizados, 8) colgajos microvasculares libres. ${ }^{(21)} \mathrm{Al}$ elegir un procedimiento reconstructivo, se debe preferir seleccionar aquel que tenga la menor morbilidad a la vez que ofrezca la mayor probabilidad de éxito funcional y estético. ${ }^{(13,15-17,19,22,23)}$

El segundo concepto más importante en la reconstrucción involucra la comprensión adecuada de la anatomía y regiones topográficas de la cara. ${ }^{(15,17,21,22)}$ La nariz se divide en subunidades respecto a sus diferentes estructuras de soporte, calidad de la piel y contorno. ${ }^{(11,20,25-27)} \mathrm{El}$ "principio de subunidades" indica que si un defecto afecta más del $50 \%$ de una subunidad, se debe considerar descartar el tejido adyacente normal para tapizar toda la subunidad con el colgajo, en lugar de simplemente parchar el defecto; esto restaura la uniformidad de la calidad de la piel, camufla los bordes de la cicatriz y utiliza la contracción de la superficie profunda del colgajo para recrear la convexidad uniforme de la punta nasal. ${ }^{(15,25,28)}$ La simetría es vital. ${ }^{(24)}$ Cuando un defecto afecta dos o más unidades, se denominan defectos compuestos. ${ }^{(25)}$

El tercer concepto es seguir el principio de "sustituir con su semejante". Este es el más importante. Para grandes defectos nasales, esta filosofia obliga a replicar el revestimiento interior, recrear el marco del subsuelo, y restaurar un adecuado grosor, textura y color de la piel. ${ }^{(12,21,25)}$

El cuarto concepto de importancia es el prevenir déficits funcionales como lo pueden ser laobstrucción de la vía aérea y la incompetencia oral. $^{(21)}$

\section{Cierre primario y por segunda intención}

El cierre directo se puede lograr con heridas menores a $1 \mathrm{~cm}$ de diámetro ${ }^{(13,16)}$ y donde exista suficiente laxitud del tejido para que los bordes de la herida se puedan aproximar bajo mínima tensión. Se deben mantener las suturas en un plano profundo para evitar los camanances permanentes. ${ }^{(13)}$ El cierre linear produce una cicatriz simple y predecible que suele ser estéticamente ideal. Desafortunadamente, hay áreas de la nariz donde el tejido es poco móvil por lo que esto no se puede realizar, particularmente en la punta nasal y alas. De esta manera, el cierre linear se suele limitar a pared nasal lateral y dorso nasal central. $^{(16)}$ 
El cierre por segunda intención puede dejar resultados estéticamente aceptables cuando la herida es pequeña y superficial $(<1 \mathrm{~cm}$ diámetro y $<4-5 \mathrm{~mm}$ profundidad), y se sitúa en ciertas áreas como la concavidad de la raíz nasal en el área del canto medial o en la concavidad del surco alar, a más de 5-6mm de distancia del margen alar móvil. ${ }^{(16)}$

\section{Injertos cutáneos}

Los injertos cutáneos se utilizan cuando otros métodos de reconstrucción como el cierre por primera o segunda intención o colgajos locales son inapropiados, inaccesibles, o producirían un resultado subóptimo. ${ }^{(29)}$

Los injertos de espesor parcial, dependiendo el grado de dermis presente se pueden dividir en delgados (0.008-0.012 mm), de espesor medio $(0.012-\quad 0.018 \mathrm{~mm}) \quad$ y gruesos $\quad(0.018-0.030$ $\mathrm{mm}) .{ }^{(26,29)}$ A menor cantidad de dermis presente, menor contracción primaria, mayor contracción secundaria, y mejor probabilidad de sobrevida. ${ }^{(26)}$

Pueden utilizarse bajo ciertas condiciones, sin embargo el resultado estético no es ideal ya que el injerto suele contraerse e hiperpigmentarse. ${ }^{(26,29)}$ Por esto, y dado que hay otras alternativas de reconstrucción, este injerto se utiliza principalmente cuando la estética no es la principal preocupación o cuando el defecto a ser corregido es de tamaño tal que no se puede utilizar un injerto de espesor total. ${ }^{(29)}$ Tambiénse considera para proporcionar cobertura biológica/funcional de la herida, es decir cuando un paciente no tolera mayor cirugía o cuando se encuentra en observación por persistencia tumoral. ${ }^{(16,29)}$

Los injertos de espesor totalpor definición incluyen a la epidermis y la capa completa de dermis del sitio donador, sin el tejido subcutáneo subyacente. $^{(26)}$ Pueden utilizarse para lograr excelentes resultados cuando el sitio donador se selecciona apropiadamente y cuando tanto el injerto donador como el lecho receptor se preparan adecuadamente a la hora de suturar el injerto en su lugar. Se utiliza en defectos en los cuales en tejido adyacente es inmóvil o escaso, o presenta lesiones premalignas o malignas, contraindicando el uso de un colgajo. ${ }^{(29)}$

Típicamente los injertos de espesor total dan un mejor resultado estético que los de espesor parcial; se contraen menos, mantienen un color más natural y suelen mantener características de textura que reflejan la calidad del sitio donador. Es aceptable utilizarlo para reconstruir la punta nasal y ala cuando no hay mucha experiencia en el uso de colgajos, ya que de otra manera se $\underset{(16)}{\text { sufriría el riesgo de causar gran distorsión nasal. }}$

El injerto de Burow(o injerto de oreja de perro) es un injerto de espesor total que utiliza la piel laxa adyacente como sitio donador. ${ }^{(30,31)}$ Es una técnica sencilla donde luego de realizar una escisión circular de la lesión cutánea, la línea de escisión se alarga siguiendo las líneas de tensión relajadas de la piel. Se crea un defecto triangular secundario al remover piel que luego se utiliza como sitio donador. ${ }^{(30,32)} \mathrm{Al}$ cerrar una parte de la herida de manera linear, la oreja de perro remanente se dona como injerto. Este permite reducir el tamaño del injerto, minimizando la visibilidad cosmética del mismo. ${ }^{(16)}$ La proximidad del sitio donador proporciona un excelente resultado dado que el color, textura y grosor de la piel son similares al sitio receptor. ${ }^{(31,32)}$

Los injertos compuestos además de contener epidermis y dermis del sitio donador suelen incluir tejido subcutáneo, cartílago y pericondrio, e incluso músculo. ${ }^{(26,33)}$ Se utilizan para la corrección de varios defectos cutáneos de grosor total. Suelen tomarse de la oreja con sitios donadores como el hélix, antehelix, concha y lóbu$10^{(27,34)}$ y utilizarse para reparar pérdidas del margen alar o de las narinas. Suelen proporcionar muy buenos resultados si son menores de $1.5 \mathrm{~cm}$ y se sitúan sobre un lecho bien vascularizado, inmovilizado. Su principal ventaja es su simplicidad. $^{(34,35)}$

\section{Técnicas de reconstrucción de un paso}

Sólo los defectos nasales pequeños se pueden reparar con técnicasde un solo tiempo quirúrgico. Los colgajos de rotación, los colgajos de transposición, las plastías en $\mathrm{V}-\mathrm{Y}$, los colgajos bilobulados y los colgajos subcutáneos pediculados de deslizamiento son las técnicas estandarizadas. $^{(35)}$ Ofrecen la posibilidad de reemplazar el tejido faltante con uno de color, textura y porosidad similar. ${ }^{(16)}$

Al elegir un colgajo para realizar la reconstrucción, se debe considerar la disponibilidad de tejido en la nariz, el diámetro de la lesión, la orientación de la cicatriz respecto a las líneas de tensión, entre otros factores. ${ }^{(16,36)}$ La piel de la punta nasal y el ala es sebácea y gruesa, por lo que colgajos originados de estos sitios pueden comúnmente ocasionar asimetría de la nariz distal. ${ }^{(16)}$

Se debe considerar además la estabilidad arquitectural del ala nasal antes de realizar un colgajo a nivel nasal distal. Si el ala lateral carece de soporte, el peso adicional del colgajo causará colapso alar con consiguiente compromiso funcional. ${ }^{(16)}$ 
El colgajo de transposición rómbico es un colgajo local de espesor total ${ }^{(36)}$ que permite movilizar tejido de un área donde está más disponible a un área donde no lo está. ${ }^{(37)} \mathrm{Se}$ basa en plexos dérmico-subdérmicos de los vasos sanguíneos, y no en solo un vaso sanguíneo. ${ }^{(36)} \mathrm{Se}$ construye alrededor de un defecto que se convierte en una figura geométrica similar a un rombo con ángulos de $60^{\circ}$ y $120^{\circ}$. El colgajo entonces se crea al trazar una línea de un lado libre del rombo que intersecta una línea paralela a un lado de dicho rombo. El colgajo utiliza el área de máxima laxitud del tejido sin afectar las estructuras anatómicas que lo rodean al cerrarse. Reorienta los vectores de tensión de cierre de la herida para localizar la cicatriz resultante a lo largo de las líneas relajadas de tensión de la piel o en la unión de dos unidades cosméticas. ${ }^{(16,37)}$ Esto es importante para minimizar la distorsión alar. Suelen utilizarse mayormente a lo largo de la pared nasal lateral y la glabela. ${ }^{(16)}$

El colgajo de rotación nasal dorsales un colgajo local de avance rotacional de la piel nasal dorsal de los dos tercios superiores de la nariz y glabela hacia la nariz inferior. Permite reconstruir heridas quirúrgicas de espesor total $\leq 2 \mathrm{~cm}$ de diámetro localizadas en la mitad inferior de la nariz, a $\geq 5 \mathrm{~mm}$ del reborde alar. ${ }^{(38,39)}$ Ofrece la posibilidad de reemplazar el tejido faltante con uno de color y textura similar. ${ }^{(16)}$ Se recomienda utilizarlo en pacientes que pueden ser candidatos a una reconstrucción con colgajo frontal pero dado sus condiciones personales (por ejemplo, psicosociales) son probables a tener un seguimiento problemático. ${ }^{(38)}$

El colgajo nasolabial es un colgajo de transposición/avance útil para la reconstrucción de defectos alares laterales. ${ }^{(16)}$ Puede ser de base superior o de base inferior. El colgajo de base superior, que tiene un arco de rotación más versátil es útil para cubrir defectos de la pared lateral nasal, ala y punta; el de base inferior es útil para defectos de labio inferior y superior, piso nasal y columela. ${ }^{(2,9)}$ La piel nasolabial es el sitio donador ideal respecto al encubrimiento de la cicatriz en el pliegue nasolabial, ${ }^{(19)}$ el color y la textura emparejan adecuadamente, y la cicatriz del sitio donante es aceptable en el surco nasolabial. ${ }^{(2,16)} \mathrm{El}$ colgajo se diseña en el pliegue nasolabial de un tamaño que encaje en el defecto de manera exacta. La incisión medial del colgajo va por el surco nasolabial, y la incisión lateral no más alta que al nivel del margen inferior del defecto. El colgajo se eleva y rota en contra de manecillas del reloj y transfiere hacia el defecto. ${ }^{(2)}$ Es uno de los colgajos más útiles en la reconstrucción nasal. ${ }^{(9)}$
Tradicionalmente suele basarse en la arteria facial axial con múltiples perforadoras. Actualmente se han utilizado con base en una sola perforadora que, a pesar de ser un procedimiento más difícil, proporciona ventajas sobre el tradicional proporcionando libertad de diseño y reduciendo la morbilidad del sitio donador. Este método puede ser aplicado a defectos perinasales pequeños a moderados. ${ }^{(19)}$

El colgajo subcutáneo en $V$-Yes un colgajo de avance $^{(10)}$ que se utiliza para reparar defectos pequeños y de mediano tamaño donde se puede obtener fácilmente un buen pedículo subcutáneo. ${ }^{(40)}$ Se utiliza principalmente en reconstrucción del dorso nasal, pero también en reconstrucciones del ala nasal, y en defectos de menos de $1.5 \mathrm{~cm}$ de diámetro que no comprometen el canto. ${ }^{(2)}$ Con los márgenes libres de tumor, se diseca un colgajo en forma de $\mathrm{V}$ y con un pedículo subcutáneo se transfiere al sitio del defecto donde se convierte en un colgajo con forma de Y que involucre plexos dérmicos y subdérmicos. ${ }^{(10)}$ El colgajo bilobuladoes un colgajo de transposición $^{(16)}$ que se utiliza especialmente para defectos del tercio inferior de la nariz, siendo apropiado para defectos de espesor parcial de menos de $1.5 \mathrm{~cm}$ en el aspecto lateral de la nariz, ala $\mathrm{y}$ punta. ${ }^{(2,9,16)}$ Recibe un excelente flujo arterial de las arterias angulares y supraorbitarias. Se basa en dos colgajos con una base común que típicamente forman un arco de no más de $90-110^{\circ}$ para evitar que se desarrolle tensión en el cierre de la herida. El ángulo entre el defecto y el primer lóbulo es igual al que hay entre el primer lóbulo y el segundo. El colgajo primario cierra el defecto tumoral y el colgajo secundario, localizado en un área de mayor movilidad cutánea cierra el sitio donador del primer colgajo. El sitio donador del colgajo secundario se cierra por primera intención. ${ }^{(2,9)}$ Para minimizar la distorsión, tanto el lóbulo primario como el secundario deben ser del mismo tamaño que los sitios receptores. ${ }^{(16)}$

Ofrece la posibilidad de reemplazar piel faltante en el aspecto distal de la nariz con piel de calidad similar que se obtiene de áreas nasales más proximales. $^{(16)}$

\section{Técnicas reconstructivas de múltiples pasos}

Defectos faciales masivos deben ser abordados en varios pasos. Inicialmente, se utiliza tejido distante para proporcionar soporte y protección a estructuras vitales, revascularizar la herida, y reconstruir una plataforma estable. Luego, se intenta restablecer la calidad de la piel, el delineado de los bordes y el contorno tridimensional con un abordaje por subunidades. ${ }^{(15)}$ 
La frente se ha tomado como el mejor sustituto de la piel nasal dado su color y textura. Bien vascularizado y adjacente a la nariz, es el material donante ideal. ${ }^{(15,41,42)}$

El colgajo frontal de línea media es un colgajo de avance que se realiza en dos o tres pasos para la reconstrucción de defectos quirúrgicos grandes y profundos de la nariz distal, especialmente donde la estructura cartilaginosa ha sido afectada. ${ }^{(13,35)}$

Es la técnica estandarizada para grandes defectos cutáneos. No solo proporciona un óptimo color y textura sino que lleva su propia vascularidad y puede nutrir injertos subyacentes. ${ }^{(9,23)}$ Es el método de elección para cerrar defectos nasales que no son candidatos a opciones de reconstrucción más sencillas, como aquellos defectos mayores a $2.5 \mathrm{~cm}-3 \mathrm{~cm}$ de diametro. ${ }^{(2,13)}$ Puede servir para cubrir cualquier reconstrucción nasal desde una pérdida severa de punta y ala hasta un defecto nasal completo. Se basa en los paquetes vasculares supratrocleares. $^{(2,5,13,16)}$

Millard lo describe "con forma de gaviota"(15): el eje vertical del colgajo se coloca sobre la línea media de la frente, y las alas yacen en los pliegues transversales naturales. El cuerpo de la gaviota yace sobre el puente y sus alas cubren las alas nasales y se pliegan hacia las narinas, la cabeza y cuello de la gaviota crean la punta y columela. El sitio donador en la frente se cierra por primera intención..$^{(2,5,13,15,16)} \mathrm{Si}$ la altura de la frente no es suficiente, el colgajo se puede elongar efectivamente modificando incisiones en la base del pedículo y bajando el punto de rotación o puede requerir realizar una expansión del tejido frontal, sin embargo esto no es necesario en la mayoría de los casos. ${ }^{(11,15)}$

Tradicionalmente, en una primera etapa, el músculo frontal y el tejido subcutáneo se extirpan distalmente y el colgajo adelgazado parcialmente se inserta en el sitio receptor. ${ }^{(15,42)}$ En una segunda etapa, 3 semanas después de la transferencia original del colgajo se divide el puente, integra el colgajo y reconstruye la anatomía de la ceja. $(9,15,23,35,42)$

A la hora de la transferencia inicial, se expone una superficie subdérmica herida y sangrante, que es propensa a la fibrosis y contracción, $y$ crea un colgajo menos probable a tolerar la tensión de cierre.

Para evitar estos defectos, la técnica se modificó. Se agregó un procedimiento extra entre la transferencia y la división. Esta técnica en tres etapas asegura un suministro de sangre óptimo, un colgajo de recubrimiento delgado, una exposición quirúrgica sin obstáculos, y un uso máximo de las opciones de recubrimiento. Se mejoran los resultados estéticos y se disminuye la necesidad de una revisión tardía. ${ }^{(15,42)}$

El colgajo frontal de tres pasos es útil para defectos de espesor total y parcial, sin importar el tamaño o profundidad. Es especialmente útil en fumadores que están en riesgo de necrosis del colgajo, y en pacientes con defectos nasales grandes que requieren un amplio adelgazamiento del colgajo de recubrimiento, especialmente cuando el diseño del colgajo requiere extensión alar y a columela. ${ }^{(15)}$

Estéticamente, dado que la nariz es más importante que la frente, se sacrifica una cicatriz en la frente para reconstruir la parte distal de la nariz con un sitio donador aceptable. ${ }^{(16,23,35)}$ Se puede ocasionar en algunos pacientes una leve migración medial de las cejas. ${ }^{(16)}$

\section{Reparación del tapizado nasal interno}

Burget y Menick ${ }^{(15,43,44)}$ describen como la mucosa intranasal bien vascularizada puede utilizarse para la mayoría de los defectos nasales, proporcionando revestimiento para defectos laterales, heminasales e incluso totales.

El colgajo de tapizado intranasales uncolgajo bipediculado de tapizado vestibular residual que puede incidirse en el área intercartilaginosa a la hora de la rinoplastia. Este colgajo se basa en el septum a nivel medial, y lateralmente en la base alar. Una vez liberado, se desplaza inferiormente para reemplazar el margen de narinas. El sitio donador puede ser reparado con un injerto cutáneo o con un colgajo septal ipisi o contralateral. ${ }^{(34)}$

Estos colgajos son delgados y flexibles; permiten colocar piezas cartilaginosas formadas individualmente que le dan forma a la piel que las recubre. Estos injertos de soporte no solo recrean la apariencia de una nariz, sino que le dan forma y soporte al tapizado restaurado y a la vía aérea. Su principal limitación es su dimensión; a medida que el tamaño del defecto aumenta, la capacidad de la técnica se sobrepasa y se corre el riesgo de que su margen distal se necrose. La narina reconstruida puede ser muy pequeña, causando estenosis y malposición del margen nasal. ${ }^{(34)}$

\section{Defectos nasales más complejos y pérdida total de la nariz}

Si el carcinoma basocelular ha invadido localmente de manera tal que el septum nasal se pierde, y siendo esta la estructura de soporte central de la nariz, se debe comenzar por reconstruir la parte anterior del septum nasal. El soporte septal remanente a nivel dorsal debe ser reimplantado ventralmente, y la mucosa debe avanzarse como un colgajo de rotación bilateral. Si bien esto 
causa un defecto septal posterior, esto causa problemas menores para el paciente quien simplemente debe adecuar su higiene nasal. Para mayor viabilidad, se puede demorar un par de semanas un siguiente procedimiento donde por medio de colgajos cutáneos invertidos de las mejillas se reconstruya el recubrimiento interno respiratorio.

En caso de requerir reemplazar todo el soporte de la nariz, se puede requerir utilizar cartílago costal. Esto dará estabilidad para toda la vida. ${ }^{(35)}$ La piel de la nariz se reconstruye con un colgajo frontal en tres pasos, sin embargo el área donadora de la frente no se puede cerrar por primera intención dado el gran tamaño del defecto, por lo que se aproxima y se deja cerrar por segunda intención.

La prioridad es reconstruir adecuadamente narinas amplias y liberar los pasajes respiratorios. En caso de defectos grandes donde no hay suficiente material local, se puede reconstruir la capa interna en una cirugía preliminar con un colgajo libre fasciocutáneo microvascular. Posteriormente, unas cuatro a cinco semanas, se asegura una perfusión retrógrada a lo largo de los bordes de la herida. El tejido subcutáneo debe ser luego adelgazado y la nariz externa reconstruida con un soporte cartilaginoso y un colgajo frontal en tres pasos. ${ }^{(35)}$

\section{Periodo de espera y planeamiento de la re- construcción}

El momento adecuado para la reconstrucción nasal luego del tratamiento del tumor es debatido. Aún luego de una resección tumoral total, la posibilidad de recurrencia nunca se puede despreciar. Dado la complejidad de la reconstrucción, y la dificultad de la exploración por recurrencias una vez realizada, se debe asegurar contar con márgenes libres de tumor para poder planear las próximas cirugías, junto con el grado tumoral, el tipo y el estadio en que se encuentra. De requerir tratamiento adyuvante, este debe de realizarse inmediatamente luego de la extirpación tumoral. ${ }^{(35)}$

Fischer et al ${ }^{(35)}$ advierten esperar un mínimo de un año en el caso de carcinomas y de dos años en el caso del cáncer basocelular tipo esclodermiforme. Recomiendan cubrir el defecto temporalmente con una férula nasal.

\section{Revisión del Procedimiento}

Casi todas las reconstrucciones complejas y algunas más simples van a requerir de una revisión tardía para restablecer una apariencia y función normal, intentando establecer una simetría ideal. ${ }^{(28,45)}$
Tanto el defecto original como la técnica de reparación determinarán el resultado final y la posibilidad de complicaciones. La meta debe ser el restaurar una dimensión correcta, volumen, posición, proyección, simetría, calidad de la piel, bordes y contornos. ${ }^{(45)}$

En una "revisión menor", la dimensión, volumen, y posición de la nariz son satisfactorias, pero los contornos nasales son imperfectos, los márgenes de narinas asimétricos, las vías aéreas pequeñas o la cicatriz en sitio donante y otra menos que lo ideal. Usualmente estos problemas locales se pueden resolver en una etapa.

En una "revisión mayor", cuando la nariz no tiene forma y se encuentra abultada, para lograr su escultura, se debe abordar con incisiones laterales a lo largo de los bordes del colgajo. Esto permite una gran exposición para poder realizar una escisión extensa de tejido blando e injertos cartilaginosos. Meses después, puede ser necesario realizar otra revisión para mejorar contornos. $^{(45)}$

\section{Contraindicaciones para la reconstrucción nasal}

Si el paciente tolera adecuadamente la remoción del tumor, probablemente tolerará de la misma manera la reconstrucción. ${ }^{(16,22)}$ Se debe tener cuidado cuando se han realizado procedimientos quirúrgicos previos o radioterapia que han alterado la nariz, porque así la perfusión de los tejidos nasales se vuelve altamente impredecible. ${ }^{(16)}$ Contraindicaciones para el uso de injertos de espesor parcial incluye la necesidad de colocarlo en un área estéticamente importante o donde una contracción significativa comprometería la función.

Los injertos de espesor total se contraindican cuando el lecho receptor, por falta de un adecuado suministro sanguíneo, no pueden sostener el injerto dado el riesgo de necrosis; al igual que un sangrado incontrolado ya que la formación de un hematoma y/o seroma compromete la sobrevida del injerto. ${ }^{(29)}$

Una contraindicación para poder realizar el colgajo frontal sería relacionado con problemas anatómicos. Cicatrices horizontales profundas a lo largo de la base de la frente pueden evitar una movilización exitosa del colgajo. Cicatrices pequeñas superficiales pueden ser aceptables. Una historia de colgajos frontales anteriores no es necesariamente una contraindicación. ${ }^{(23)}$

Existen ciertas condiciones que pueden tener un impacto negativo en el éxito de la reconstrucción como lo son el fumado excesivo, diátesis sanguíneas, malnutrición crónica, enfermedad severa subyacente, y expectativas irreales por parte del 
paciente. ${ }^{(16,22,46)}$ Idealmente, estas condiciones deben de ser abordadas antes de la reconstrucción. ${ }^{(22)}$

Una contraindicación absoluta es la presencia enfermedad residual o márgenes quirúrgicos inciertos. $^{(17,22)}$

\section{Complicaciones de la reconstrucción nasal}

Las complicaciones de la reconstrucción nasal pueden ocurrir de manera temprana o tardía en el curso postoperatorio. ${ }^{(47)}$

Sin la experiencia adecuada, los resultados pueden ser desastrosos pero con la adecuada experiencia, ofrece muchas ventajas. ${ }^{(16)}$

Complicaciones tempranas incluyen el sangrado, la infección y la necrosis del colgajo. ${ }^{(16,47)}$ Los factores de riesgo más comunes para el sangrado perioperatorio son la presencia de hipertensión, uso de medicamentos antiplaquetarios, y un exceso en la actividad física. El sangrado suele ser más común de la superficie inferior del colgajo o de los bordes de revestimiento mucoso.

El riesgo de infección es poco común dado que el suministro sanguíneo de la nariz y de los colgajos externos y de revestimiento utilizados es abundante.

Existen varios grados de necrosis de un colgajo. La necrosis superficial se manifiesta como una pérdida epidérmica (epidermólisis) que suele sanar con pocas consecuencias. La necrosis de espesor total (involucrando dermis y tejido subcutáneo) suele afectar el aspecto más distal del colgajo; puede manejarse de manera conservadora si el área comprometida es pequeña o está en un área donde la cicatrización secundaria no causa distorsión de márgenes. De otra manera puede requerir una movilización completa del colgajo, remoción del área necrótica y avance del restante del colgajo para reparar el defecto. $\mathrm{Si}$ hay una necrosis completa del colgajo con infección simultánea, se debe desbridar la escara y dejar sanar por segunda intención. ${ }^{(47)}$

Dado la importancia estética de la nariz, la necrosis del tejido puede tener efectos devastadores. El riesgo es mayor en injertos que en colgajos, sin embargo hay ciertas precauciones que se pueden tomar para evitar esta complicación co- mo una preparación adecuada del lecho receptor, un diseño adecuado del colgajo, minimizar la tensión a la hora de cerrar la herida, realizar una hemostasia meticulosa, entre otros. ${ }^{(16)}$

Dentro de las complicaciones tardías se pueden presentar mala cicatrización, obstrucción de la vía aérea nasal, anormalidades en la pigmentación cutánea y anormalidades vasculares. Cierto grado de obstrucción nasal se considera común durante los primeros 2 a 3 meses. Esto suele mejorar con el tiempo a medida que el lecho de tejido cicatricial por debajo del colgajo se suaviza y madura. La obstrucción persistente puede ocurrir cuando hay afección de dos o más unidades nasales, especialmente si hay afección del ala o pared nasal lateral. Esto suele requerir reparación quirúrgica.

Numerosos cambios cutáneos y vasculares pueden ocurrir. El cambio cutáneo más común es el desarrollo de una dermatitis por contacto. La hiperpigmentación cutánea se suele observar en pacientes con piel Fitzpatrick tipo III o mayor y es más frecuente con el uso de injertos que con colgajos; suele resolver con el tiempo y la fotoprotección. En ciertos casos se puede observar hipopigmentación. Se puede desarrollar también eritema del colgajo o del injerto por hipervascularidad capilar que suele disminuir con la cicatrización. Pueden desarrollarse telangiectasias. ${ }^{(47)}$

\section{CONCLUSIÓN}

El carcinoma basocelular es una de las principales etiologías que van a requerir de la reconstrucción nasal. La técnica de dicha reconstrucción va a depender de numerosos factores tales como el sitio donador, el sitio receptor, el defecto a reparar, la técnica empleada y la experiencia del cirujano.

La nariz es la parte más prominente de la cara, y existiendo tantas opciones quirúrgicas, se debe saber elegir la más adecuada recordando que aunque los resultados pueden ser óptimos, sin la experiencia o la elección adecuada, el resultado puede ser desastroso. 


\section{BIBLIOGRAFÍA}

1. Bader RS Santacroce L Diomede L Kennedy AS. Basal Cell Carcinoma. Medscape. Marzo 2014. http://emedicine.medscape.com/article/ 276624-overview Accesado: 28 mayo, 2014.

2. Nakayama M Tabuchi K Nakamura $\mathrm{Y}$ Hara A. Basal Cell Carcinoma of the Head and Neck. J Skin Cancer. 2011;2011:496910.

3. Neville JA Welch E Leffel DJ Management of Nonmelanoma Skin Cancer in 2007. Nat Clin Pract Oncol. 2007;4(8):432-469.

4. Kannan R John R. Reconstruction of Ala of Nose with Bilobed Flap: A 2 Year Follow-up. J. Maxillofac. Oral Surg. 2011;10(1):57-59.

5. Rao J Deora H. Surgical Excision with Forehead Flap as Single Modality Treatment for Basal Cell Cancer of Central Face: Single Institutional Experience of 50 Cases. Journal of Skin Cancer 2014:32072.

6. Ouyang YH. Skin Cancer of the Head and Neck. Semin Plast Surg 2010;24:117-126.

7. Migliano E Bellei B Govoni FA Bucher S Picardo M. Fat and epidermal cell suspensión grafting: a new advanced one-step skin regeneration surgical technique. Journal of Experimental \& Clinical Cancer Research 2014, 33:23.

8. Cigna E Tarallo M Maruccia M Sorvillo V Pollastrini A Scuderi N. Basal Cell Carcinoma: 10 Years of Experience. Journal of Skin Cancer 2011:476362.

9. Fata J. Principles and Techniques of Nasal Reconstruction. Medscape. Setiembre, 2013. http://emedicine.medscape.com/article/ 1820512-overview. Accesado: 28 mayo, 2014.

10. Kwon KH Lee DG Koo SH Jo MS Shin $\mathrm{H}$ Seul JH. Usefulness of $V$ - $Y$ Advancement Flap for Defects after Skin Tumor Excision. Arch Plast Surg 2012;39:619625.

11. Menick FJ. Paramedian Forehead Flap Nasal Reconstruction. Medscape. Mayo 2013.

http://emedicine.medscape.com/article/ 1293154-overview. Accesado 09 junio, 2014.
12. Gladstone HB. Algorithm for the Reconstruction of Complex Facial Defects. Skin Therapy Letter. 2007;12(2).

13. Salgarelli AC Bellini P Multinu A et al. Reconstruction of Nasal Skin Cancer Defects with Local Flaps. Journal of Skin Cancer 2011:181093.

14. Agostini T Perello R Lo Russo G Spinelli G. Through-and-through Nasal Reconstruction woth the Bi-Pedicled Forehead Flap. Arch Plast Surg. 2013;40:748-743.

15. Menick FJ. Nasal Reconstruction: Forehead Flap. Plast. Reconstr. Surg. 2004;113(6):100e-111e.

16. Cook J. Nasal Reconstruction. Medscape.Marzo, 2011. http://emedicine.medscape.com/article/ 1820151-overview Accesado: 04 junio 2014.

17. Langford FP J. Nasal Reconstruction Following Soft Tissue Resection. Medscape.Junio 2013. http://emedicine.medscape.com/article/ 880073-overview. Accesado 05 junio 2014.

18. Namdev LN Darbari A. Nasal Reconstruction with Forehead Flap: Our Experience. Indian J Otolaryngol Head Neck Surg 2013;65(2):177-180.

19. Yoon TH Yun IS Rhan DK Lee WJ. Reconstruction of Various Perinasal Defects Using Facial Artery PerforatorBased Nasolabial Island Flaps. Arch Plast Surg. 2013;40:754-760.

20. Menick FJ. Complex Nasal Reconstruction: A Case Study: Composite Defect. Facial Plast Surg Clin N Am 2011;19(1):197-211.

21. Azizzadeh B. Facial and Nasal Cancer Reconstruction Case Study. Medscape. Noviembre, 2011. http://emedicine.medscape.com/article/ 880171-overview. Accesado: 28 mayo, 2014.

22. Sajjadian A. Nasal Reconstruction. Medscape. $\quad$ Febrero, 2010. http://emedicine.medscape.com/article/ 876456-overview. Accesado 05 junio, 2014.

23. Park SS. Forehead Flaps. Medscape. Mayo, 2013. http://emedicine.medscape.com/article/ 880171-overview. Accesado: 28 mayo, 2014. 
24. Menick FJ. Paramedian Forehead Flap Nasal Reconstruction. Medscape. Mayo 2013.

http://emedicine.medscape.com/article/ 1293154-overview. Accesado 09 junio, 2014.

25. Menick FJ. Defects of the Nose, Lip, and Cheek: Rebuilding the Composite Defect. Plast. Reconstr. Surg. 2007;120:887-898.

26. Losee JE Gimbel M Rubin J Wallace CG Wei F. Chapter 45. Plastic and Reconstructive Surgery. En: Brunicardi F.; Andersen D.K.; Billiar T.R.; Dunn D.L.; Hunter J.G.; Matthews J.B.; et al. Schwartz's Principles of Surgery, 9na edición.New York, NY: McGraw-Hill; 2010.

http://accesssurgery.mhmedical.com.ez proxy.sibdi.ucr.ac.cr:2048/content.aspx ?bookid=352\&Sectionid $=40039787$.

Accesado 11 junio, 2014.

27. Son D Kwak M Yun S Yeo H Kim J Han K. Large Auricular Chondrocutaneous Composite Graft for Nasal Alar and Columellar Reconstruction. Arch Plast Surg. 2012;39:323-328.

28. Menick FJ. Aesthetic and reconstructive rhinoplasty: A continuum. J Plast Reconst Aesth Surg. 2012;65:1169-1174.

29. Grande DJ. Skin Grafting. Medscape. Junio, 2013. http://emedicine.medscape.com/article/ 1129479-overview. Accesado 09 junio 2014.

30. Cabeza R Leis V Campos M De La Cueva P Suárez, R Lázaro, P. Burrow`s grafts in the facial region. Journal of the European Academy of Dermatology and Venerology 2006;20(10):12661270.

31. Zitelli JA. Burow's grafts. Journal of the Americal Academy of Dermatology. 1987;17(2):271-279.

32. Gençoğlan G Karaarslan I Dereli $T$. Closure of Surgical Defect with "DogEar Graft" in Basal Cell Carcinomas. J Turk Acad Dermatol 2007;1(2):71201c.

33. Inchingolo F Tatullo M Marrelli M et al. Clinical case-study describing the use of skin-perichondrium-cartilage graft from the auricular concha to cover large defects of the nose. Head \& Face Medicine 2012, 8:10.
34. Menick FJ. The Evolution of Lining in Nasal Reconstruction. Clin Plast Surg. 2009;36(3):421-441.

35. Fischer H Gubisch W. Nasal Reconstruction. A Challenge for Plastic Surgery. Dtsch Arztebl Int 2008;105(43):741-6.

36. Sclafani A. Rhombic Flaps. Medscape. Junio, 2013. http://emedicine.medscape.com/article/ 879923-overview. Accesado 11 junio, 2014.

37. Chatrath V. Transposition Falps Treatment \& Management. Medscape. Marzo, 2014.

http://emedicine.medscape.com/article/ 1129028-treatment. Accesado 10 junio, 2014.

38. Eren E Beden V. Beyond Rieger `s original indication; the dorsal nasal flap revisited. Journal of Cranio-MaxilloFacial Surgery 2014;42:412-416.

39. Zimbler M. The Dorsal Nasal Flap for Reconstruction of Large Nasal Tip Defects. Dermatol Surg 2008;34:571-574.

40. González B Pérez A Otero MM Rodríguez MA. Subcutaneous pedicled $V-Y$ advancement flap for surgical reconstruction of the auricle of the ear. Actas Dermosifiliogr, 2014;105(4):e23-6.

41. Özkan Ö Coskunfirat K Özkan Ö. Midface Reconstruction. Semin Plast Surg 2010;24:181-187.

42. Menick FJ. A 10-Year Experience in Nasal Reconstruction with the ThreeStage Forehead Flap. Plast. Reconstr. Surg. 2002;109:1839-1855.

43. Burget G Menick FJ. Nasal support and lining: The marriage of beauty and blood supply. Plast. Reconstr. Surg.1989;84:189.

44. Burget GC Menick FJ. Aesthetic Reconstruction of the Nose. St. Louis, Mo.: Mosby, 1994.

45. Menick FJ. An Approach to the Late Revision of a Failed Nasal Reconstruction. Plast. Reconstr. Surg. 2012;129:92e.

46. Little SC Hughley BB Park SS. Complications with forehead flaps in nasal reconstruction. Laryngoscope 2009;119(6):1093-1099.

47. Naficy S Baker SR. Chapter 16: Complications and Management. En Baker SR. Principles of Nasal Reconstruction. 2da edición. New York, NY; Springer 
Science+Business Media; 2011. Pp: 413-456.

\section{CONFLICTOS DE INTERES}

Los autores declaran que no existe ningún conflicto de interés. 